\title{
Acute inferior myocardial infarction: the dilemma between anatomic-pathological classification and electrocardiographic diagnosis
}

\author{
Boon Lock $\underline{C h i a}^{1,2, *}$, MBBS, FRACP, James $\underline{\text { Yip }}^{1,2}$, MBBS, FRCP, Kian Keong $\underline{P o h}^{1,2}$, MBBChir, FRCP
}

T he anatomic-pathological definition of acute inferior myocardial infarction (AIMI) or inferior ST elevation myocardial infarction (STEMI) has, for decades, recognised infarction of the inferior wall of the left ventricle as the key abnormality. This segment of the heart is supplied by the posterior descending artery, which is much more commonly a branch of a dominant right coronary artery rather than a branch of a dominant left coronary circumflex artery. ${ }^{(1)}$ Since a non-dominant right coronary artery and a non-dominant left coronary circumflex artery do not have this branch, occlusion of both these non-dominant arteries will not anatomically produce infarction of the left ventricular inferior wall. In normal human beings, the right coronary artery is dominant in $85 \%$ of cases and the left circumflex artery in $7 \%$ of cases, while both these arteries are co-dominant in $7 \%$ of cases. ${ }^{(2)}$

On the other hand, with regard to the electrocardiogram (ECG), AIMI has for decades, been diagnosed if there is ST elevation in two or more contiguous leads in leads II, III and aVF. Apart from AIMI, ST elevation in these three inferior leads can also be due to other conditions such as acute pericarditis and acute myocarditis. ${ }^{(3,4}$ For many years in the ECG literature, it has been described that ST elevation in lead III > ST elevation in lead II indicates right coronary artery occlusion (Fig. 1a), and that ST elevation in lead II $\geq$ ST elevation in lead III indicates left circumflex artery occlusion (Fig. 1b). ${ }^{(5,6)}$ There was no mention of whether either of these two arteries were dominant, although it was frequently assumed by readers that the right coronary arteries were dominant and the left circumflex arteries were non-dominant.

Recently, it was reported that occlusion of a dominant left circumflex artery will produce ST elevation in leads II, III and aVF with ST elevation in lead III > ST elevation in lead II (exactly like that seen in a dominant right coronary artery occlusion). ${ }^{(7)}$ In fact, this is completely to be expected, because in both these situations, the posterior descending artery is occluded, resulting in ischaemia of the inferior wall of the left ventricle.

Some authors today incorrectly believe that in a patient with ST elevation in the inferior leads, where ST elevation in lead II $\geq$ ST elevation in lead III, AIMI has occurred due to occlusion of a non-dominant circumflex artery. This belief is illogical, because a non-dominant left coronary circumflex artery does not have the posterior descending artery and because of this, AIMI cannot have occurred. In such a situation, which part of the left ventricle (if it is not the inferior) is infarcted?

In the future, detailed studies should be performed of AIMI patients with various types of coronary occlusions correlating with the ECG changes, such as non-dominant left circumflex artery occlusion. These correlations, together with echocardiographic or magnetic resonance imaging evaluation of the left ventricle, should be made before any final conclusion is reached.
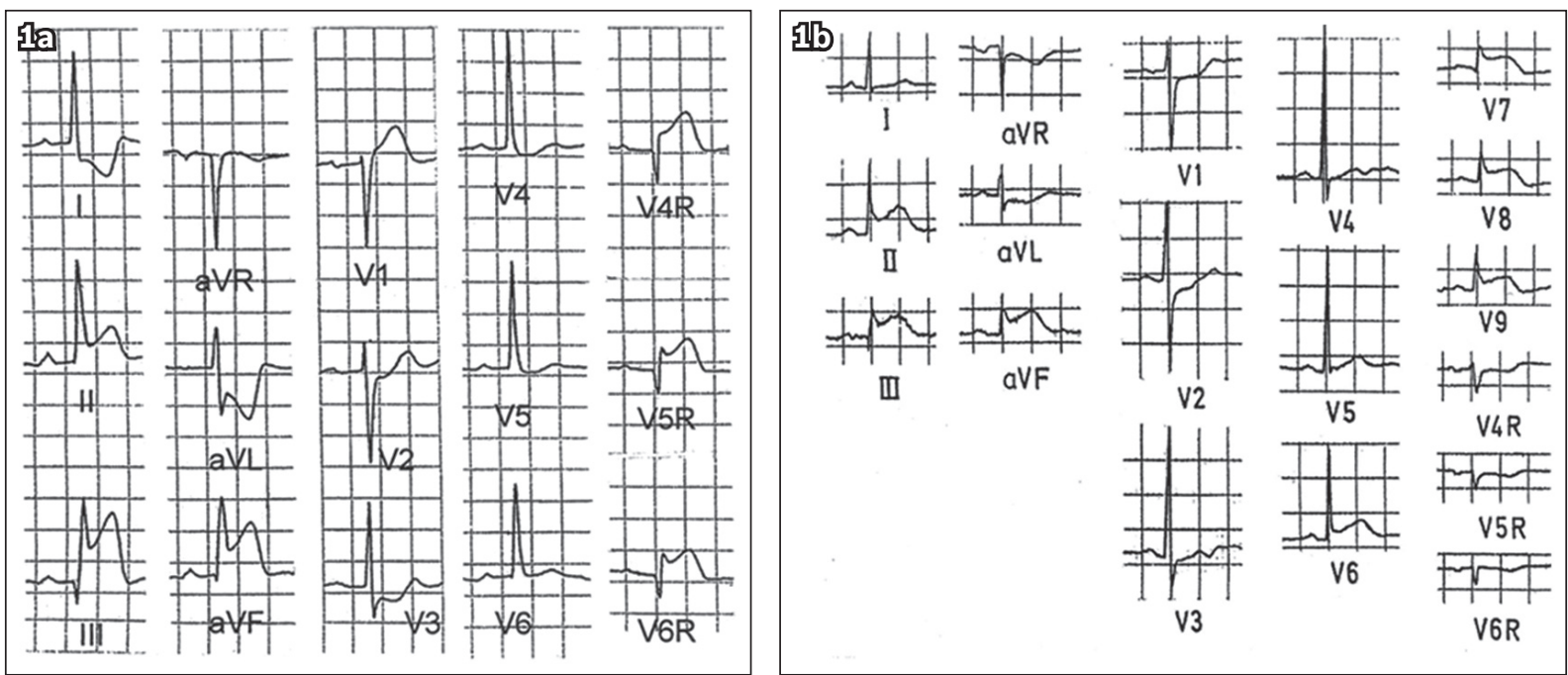

Fig. 1 ECG shows (a) ST elevation in lead III greater than that in lead II. There is ST elevation in the right-sided chest leads; and (b) ST elevation in lead II equal to or greater than that in lead III. There is concomitant ST elevation in posterior leads V7 to V9 and ST depression in the right-sided chest leads.

${ }^{1}$ NUS Yong Loo Lin School of Medicine, National University of Singapore, ${ }^{2}$ Department of Cardiology, National University Heart Centre Singapore, National University Health System, Singapore

*This author is deceased.

Correspondence: A/Prof Poh Kian Keong, Senior Consultant, Department of Cardiology, National University Heart Centre Singapore, National University Health System, 1E Kent Ridge Rd, NUHS Tower Block, Level 9, Singapore 119228. kian_keong_poh@nuhs.edu.sg 
Meanwhile, it is perhaps reasonable to retain the terminology of inferior STEMI only in patients whose ECGs show ST elevation in the inferior leads II, III and aVF and where the ST elevation in lead III > ST elevation in lead II. Most of these patients will have an occluded dominant right coronary artery and a minority have an occluded dominant left coronary circumflex artery. Patients showing ST elevation in leads II, III and aVF where the ST elevation in lead II is equal to or more than the ST elevation in lead III should not be diagnosed as AIMI. Until future studies confirm the exact site of infarction of these patients, one could postulate that it is possibly either the lateral, posterolateral or posterior segments of the left ventricle, because the major branches of a non-dominant circumflex artery include these three branches. ${ }^{(8)}$

\section{ACKNOWLEDGEMENT}

We are grateful to Ms Elisdawatinizam Binte Mahat, Management Assistant Officer, National University of Singapore, and Dr Nicholas J Ngiam, Resident, National University Health System for their help in the preparation of this editorial.

\section{REFERENCES}

1. Adams J, Treasure T. Variable anatomy of the right coronary artery supply to the left ventricle. Thorax 1985; 40:618-20.

2. Gebhard C, Fuchs TA, Stehli J, et al. Coronary dominance and prognosis in patients undergoing coronary computed tomographic angiography: results from the CONFIRM (COronary CT Angiography EvaluatioN For Clinical Outcomes: An InteRnational Multicenter) registry. Eur Heart J Cardiovasc Imaging 2015; 16:853-62.

3. Kuntjoro I, Teo SG, Poh KK. Electrocardiography series. Non-ischaemic causes of ST segment elevation. Singapore Med J 2012; 53:367-70; quiz 371.

4. Sabatine MS, Poh KK, Mega JL, Shepard JA, Stone JR, Frosch MP. Case records of the Massachusetts General Hospital. Case 36-2007. A 31-year-old woman with rash, fever, and hypotension. N Engl J Med 2007; 357: 2167-78.

5. Chia BL, Yip JW, Tan HC, Lim YT. Usefulness of ST elevation II/III ratio and ST deviation in lead I for identifying the culprit artery in inferior wall acute myocardial infarction. Am J Cardiol 2000; 86:341-3.

6. Zimetbaum PJ, Josephson ME. Use of the electrocardiogram in acute myocardial infarction. N Engl J Med 2003; 348:933-40.

7. Zhan ZQ, Wang W, Dang SY, et al. Electrocardiographic characteristics in angiographically documented occlusion of the dominant left circumflex artery with acute inferior myocardial infarction: limitations of ST elevation III/II ratio and ST deviation in lateral limb leads. J Electrocardiol 2009; 42:432-9

8. Rasoul S, de Boer MJ, Suryapranata H, Hoorntje JC, et al. Circumflex arteryrelated acute myocardial infarction: limited ECG abnormalities but poor outcome. Neth Heart J 2007; 15:286-90. 